\title{
FATORES RELACIONADOS À ENTRADA DAS MULHE- RES NO TRÁFICO DE DROGAS: ESTUDO DE CASO DO PRESÍDIO DO MUNICÍPIO DE SANTA MARIA ${ }^{1}$
}

\author{
Yasmine Assmann ${ }^{2}$ \\ Kalinca Léia Becker ${ }^{3}$
}

Resumo: $\bigcirc$ objetivo desse estudo é analisar fatores relacionados à decisão das mulheres de praticar o crime do tráfico de drogas. Para isso, foram analisadas informações dos questionários estruturados aplicados às mulheres condenadas em regime fechado, pelo crime de tráfico de drogas em um presídio, situado no município de Santa Maria - RS. Os resultados indicaram que fatores socioeconômicos como renda, escolaridade e desemprego são determinantes importantes para a entrada de mulheres no tráfico de drogas. A influência de parceiros e familiares também ganham destaque. Os questionários revelam ainda que as mulheres criminosas também já foram vítimas de algum tipo de crime.

Palavras chave: tráfico, drogas, mulheres.

Abstract: This study aims to analyze factors related to the decision of women to commit the crime of drug trafficking. For this, we analyzed information from the structured questionnaires applied to women condemned in a closed regime, for the crime of drug trafficking in a prison located in the municipality of Santa Maria - RS. The results indicated that socioeconomic factors such as income, schooling and unemployment are important determinants for the entry of women into drug trafficking. The influence of partners and family members is also highlighted. The questionnaires also reveal that criminal women have also been victims of some type of crime. Keywords: traffic, drugs, women.

\section{Introdução}

tráfico de drogas caracteriza-se como uma atividade ilegal, porém lucrativa, com uma estrutura organizacional complexa, uma cadeia produtiva específica e uma elevada capacidade de adaptação, uma vez que a cada dia são criados novos

\footnotetext{
As autoras agradecem as contribuições da Professora Olinda Barcellos, no tema relacionado à economia do crime, e da psicóloga Renata Cauduro, no processo de elaboração e aplicação dos questionários.

2 As autoras agradecem as contribuições da Professora Olinda Barcellos, no tema relacionado à economia do crime, e da psicóloga Renata Cauduro, no processo de elaboração e aplicação dos questionários.

3 Bacharel em Ciências Econômicas pela Universidade Federal de Santa Maria. E-mail: niniassmann@yahoo. com.br.
} 
processos de produção, novas drogas, formas de venda, rotas de fuga e comércio. Esse tipo de crime envolve muitos indivíduos, como os produtores de entorpecentes, os usuários, os traficantes, entre outros.

Assim, é de extrema importância entender as variáveis econômicas que geram os crimes de ordem lucrativa, como o tráfico de drogas. A idade, escolaridade, as variações na cultura e os mecanismos sociais podem explicar tendências desse tipo de crime. Outra característica do mercado ilegal do tráfico de drogas é que as mulheres vêm ganhando cada vez mais espaço, sendo o principal motivo para a detenção do gênero feminino.

Conforme dados do DEPEN de 2014, no Levantamento Nacional de Informações Penitenciárias (INFOPEN), do total de crimes cometidos pela população carcerária brasileira, $27 \%$ eram ligados ao tráfico de drogas, tornando esse o crime com maior incidência em todo país. Do total de mulheres presas, $63 \%$ eram por conta de crime ligado ao tráfico de entorpecentes e os homens correspondem a $25 \%$ do total deste mesmo crime. Isso mostra que, apesar da população carcerária ser em maioria do sexo masculino, chegando ao valor de 234.524 presos, as mulheres são maioria em crimes ligados ao comércio ilegal de drogas, correspondendo a um total de 11.297 presas no ano de 2014.

Segundo dados o Departamento Penitenciário Nacional (DEPEN) de 2014, o tráfico de drogas compõe, nos últimos anos, a atividade que mais gera o ingresso de mulheres no sistema prisional brasileiro. $O$ comércio ilegal de drogas se tornou uma indústria potente em todo mundo, obtendo um faturamento anual de US\$ 870 bilhões na primeira década do milênio, segundo o Escritório das $\mathrm{Na-}$ ções Unidas sobre Drogas e Crime (UNODC). Esses dados mostram que, apesar de as mulheres serem o gênero com menor incidência de prisões, a maioria está presa por conta do tráfico de drogas, o que revela uma característica marcante do mercado de entorpecentes, que busca alvos diferenciados para manter seu negócio e leva a cada dia mais mulheres ao crime.

Diante disso, o objetivo desse estudo é analisar os fatores que influenciam o ingresso de mulheres no mercado do tráfico de drogas. Os procedimentos metodológicos que norteiam esta pesquisa, do ponto de vista de sua abordagem geral, consistem no método indutivo, descritivo e explicativo. Trata-se de um estudo de caso, que tem como unidade de estudo uma penitenciária regional que se localiza na cidade de Santa Maria, RS. Para este procedimento utilizou-se a aplicação de questionários como forma de coleta voluntária de informações das mulheres presas e condenadas pelo crime de tráfico de drogas. 


\section{Revisão de Literatura}

\subsection{0 tráfico de drogas praticado pelas mulheres}

Os dados apresentados pelo Infopen de 2014 chamam a atenção quando são divididos por gênero masculino e feminino, mostrando uma tendência do sistema prisional brasileiro para as mulheres presas. $\mathrm{Na}$ maioria dos casos, as mulheres cumprem pena pelo crime de tráfico de drogas, diferentemente da tendência masculina, que é mais abrangente na prática de diferentes tipos de crimes, com praticamente $50 \%$ de crimes divididos em tráfico e roubo.

O gráfico 1 mostra as proporções de cada tipo de crime por gênero. As prisões femininas obedecem a padrões de criminalização muito distintos em comparação com o sexo masculino. Enquanto 25\% dos crimes pelos quais os homens respondem estão relacionados ao tráfico, para as mulheres esse valor chega a $63 \%$. Esses dados mostram uma tendência do crime de tráfico de drogas, onde, cada vez mais mulheres encontram-se praticando esse tipo de crime.

Conforme Barros et. al. (2007), para discutir a respeito do papel da mulher na sociedade, das mulheres na prática de crimes, do seu papel social ou sexual, deve-se levar em conta, como ponto de partida, seu processo de dominação social. Ou seja, o momento que a mulher passou a ter mais liberdade de gênero e teve a ampliação de suas responsabilidades, a partir do mundo capitalista, assumindo, muitas vezes, tarefas independentes de seu sexo. $O$ mesmo ocorre para com as mulheres no mundo do crime, que a partir da conquista de sua liberdade de gênero, parte para outro mercado, que neste caso, seria o ilícito. Este fato ocorre, em especial, pela forte influência que estas sofrem pelo gênero masculino, seja marido, irmão ou filho, que já esteja inserido nesse meio.

Um estudo feito por Steffensmeier e Cobb (1981), com dados do F.B. I dos anos de 1934 a 1979, sobre os prisioneiros urbanos, afirma que a criminalidade feminina aumentou proporcionalmente, de $11 \%$ a $15 \%$ em crimes de modo geral, em especial para crimes leves. Conforme os autores, o período da pesquisa foi caracterizado por um crescimento generalizado de crimes praticados pelo sexo masculino, porém a participação das mulheres aumentou ainda mais, em exceção a crimes violentos.

No que diz respeito ao ingresso de mulheres no tráfico de drogas, uma questão importante é de que elas, na maioria dos casos, desempenham o papel do elo mais vulnerável na prática desse crime, onde cumprem papéis subalternos, arriscados e com grande contato com a comunidade, sendo sua atividade mais descartável do que de seus parceiros homens. 
Gráfico 1: Distribuição por gênero de crimes tentados/consumados entre os registros das pessoas privadas de liberdade

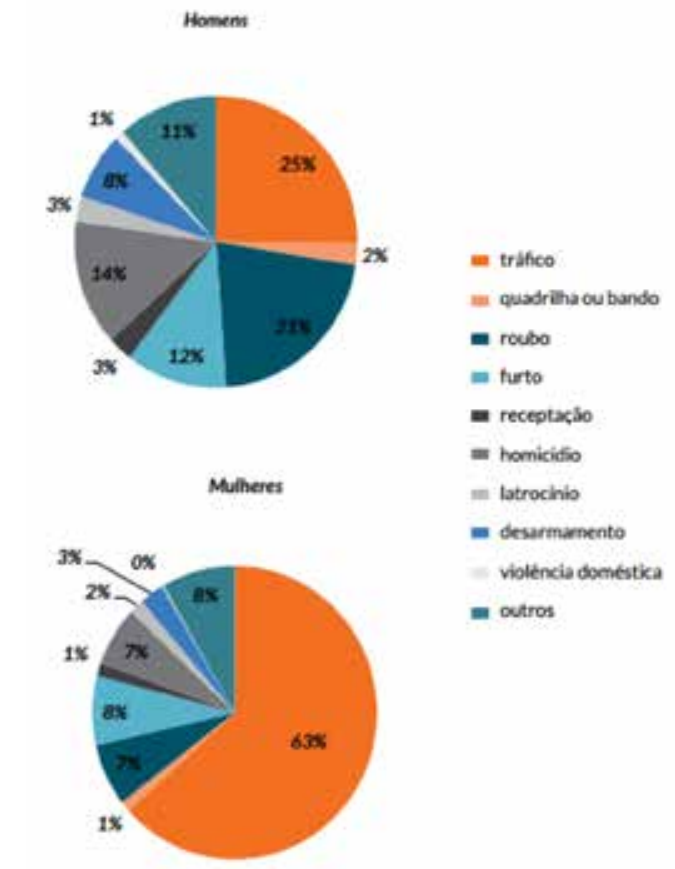

Fonte: Infopen (2014).

De maneira geral, os fatores que influenciam as mulheres a adentrar no mercado de drogas são variados, como a má distribuição de renda, dificuldade de entrar no mercado de trabalho, emprego precário, baixa escolaridade e qualificação, pobreza, entre outros. Outro fator que pode vir a influenciar o aumento de mulheres no tráfico de drogas é o envolvimento delas com homens que já estão inseridos nesse comércio ilegal, ou por meio de familiares, já que esse mercado necessita de muitos envolvidos, para o perfeito funcionamento. Assim, se a muIher estiver disposta a participar desse negócio, que muito é atrativo pelo dinheiro fácil, o mercado certamente irá a absorver, por necessitar desse tipo de mão-de-obra, que, na maioria das vezes, conforme descreve Minzon et. al. (2010) é menos julgada pela sociedade como uma possivel traficante.

Mesmo que os dados sobre a participação das mulheres em crimes ainda sejam menores que o envolvimento dos homens, os estudos mais recentes indicam uma tendência de aumento na prática de crimes pelo gênero feminino. São poucos os estudos encontrados sobre o tema, que aborde as mulheres no meio do tráfico de drogas, principalmente pela forte influência que os homens ainda exercem na iniciação das mulheres em atividades criminosas. Segundo Dutra (2012), 
o principal fator para o envolvimento feminino no comércio ilícito de drogas, seria a presença masculina como incitadora ao crime, em forma de vínculo da mulher nos crimes do marido. Esta é influenciada, de forma direta ou indireta, pelo parceiro no cometimento de crimes, onde, a partir da figura masculina, inicia-se a entrada no tráfico de drogas. Dutra destaca que esse vínculo ocorre por vários motivos, como laços emocionais e a falta de conhecimento a respeito da ilegalidade do ato praticado.

Para Jacinto (2011), as mulheres acabam por adentrar nessa atividade ilegal a partir da ligação afetiva com um parceiro já traficante, que por acaso, ficou impedido de continuar na realização dessa atividade e permitiu que sua parceira ocupasse seu lugar nessa função, para complementar a renda da família. A mulher ocupa um lugar hierárquico no tráfico de drogas quando, na maioria das vezes, a pessoa com quem tem um relacionamento afetivo vem a falecer ou ser presa, restando para ela à ocupação desse cargo ou a desistência da prática desse crime. A autora acredita também que as mulheres entram nesse meio informal como uma maneira de contribuir na economia doméstica.

Para Moura (2005), as mulheres no mercado de drogas estão ligadas ao objeto final do crime, ou seja, na frente mais arriscada do negócio, e por isso, são as primeiras a serem presas, enquanto muitos homens passam impunes à prisão. Elas têm posições mais baixas e mais expostas nesse trabalho e também recebem menos dinheiro, assim como ocorre no mercado formal de trabalho, o que, portanto deixá-las mais suscetiveis à prisão.

De acordo com Musumeci (2001), as funções das mulheres no tráfico de drogas seriam atividades mais centrais, como abastecedora, distribuidora, traficante, caixa, contabilidade, gerente e também atividades mais subalternas como consumidora, cúmplice, assistente, vendedora, entre outras. Para Musumeci (2001), a elevação de mulheres nesse tipo de crime estaria relacionado ao fato delas ocuparem, na maioria das vezes, atividades periféricas na estrutura do tráfico, sendo alvos mais fáceis para a polícia capturar, por participarem de atividades mais arriscadas. Além de que, elas também têm menos recursos para negociar a sua liberdade no momento de apreensão pela polícia.

Também para Rodrigues et. al. (2012), quanto à entrada de mulheres na criminalidade e consequentemente no sistema prisional, nota-se que elas usufruem de atividades ilícitas como método de sobrevivência. Sendo normalmente pertencentes a grupos sociais mais vulneráveis, com praticamente nenhuma escolaridade, mães de família, que vivem em áreas periféricas e se encontram na criminalidade, em especial no tráfico de drogas, como forma de seu sustento e de sua familia. Os autores notam que as mulheres tendem a ingressar nesse tipo de mercado para, muitas vezes, ajudar seus companheiros e filhos que já são traficantes.

Barcinski (2009) frisa em seu trabalho que, para entender o ingresso de cada 
vez mais mulheres e jovens no tráfico de drogas, é preciso levar em conta que nem sempre as questões sociais como pobreza, baixa renda e a falta de assistência social são as principais motivadoras desse ingresso desmedido. Apesar de refletir em grande parte a realidade dessas presas, cabe também espaço para adentrar nesse grupo mulheres de classe média e de nível médio completo, ou seja, não são todas as detentas que apresentam perfil de baixa renda e escolaridade; há exceções. Outros problemas sociais podem ser analisados também, como a falta de emprego, desejo de poder e status.

Barcinski (2009) ressalta que, apesar de os participantes das atividades criminosas, como o tráfico de drogas, admitirem existir obstáculos econômicos e sociais que levam muitos jovens e mulheres de baixa renda para esse mercado, 0 poder e o status que a maioria experimenta nesse comércio ilegal, acaba por se tornar o principal motivador para praticar-se esse tipo de crime. Quanto à entrada dessas mulheres no tráfico de entorpecentes, muitas delas vivem invisiveis socialmente por boa parte da vida e acham no tráfico uma possibilidade, muitas vezes a única, de pertencerem a um grupo criminoso, obtendo valor pessoal e poder, principalmente pelo impacto e medo que causam nos membros da comunidade, carregando armas pesadas e ganhando um salário que no mercado legal seria dificilmente alcançado.

Assim, percebe-se que existem variáveis, muitas vezes econômicas, por trás da influência no ingresso de mulheres na criminalidade, principalmente no mercado do tráfico de drogas. Seriam elas a violência familiar, a situação socioeconômica dos indivíduos, o baixo grau de escolaridade, desemprego, inflação, entre outros. Para Dutra (2012), a violência familiar seria um fator gerador da criação do comportamento criminoso, em razão de que a família seria o principal alicerce para o desenvolvimento do caráter de cada ser humano, que através de uma relação de dependência e aprendizado, desenvolve o pensamento e a consciência. Quando a familia está desestruturada, pode gerar inúmeros sofrimentos aos familiares, em razão de que ela é um alicerce, e os pais desempenham o papel de professores na vida das crianças, tornando-se a base para a construção de uma pessoa equilibrada e saudável. Os problemas sociais repercutem diretamente na estrutura e organização da família, fragilizando-a e provocando sua ineficácia no papel de formação de indivíduos honrados e éticos. Visto também que, parte das mulheres presas já sofreram algum tipo de violência familiar ou maus tratos, segundo a autora.

Dutra (2012) destaca a situação socioeconômica das mulheres, estas que encontram no tráfico uma maneira de ter uma renda estável, mesmo tendo mão de obra desqualificada, tornando-se propostas tentadoras em meio a uma economia que gera, a cada dia mais, desemprego, onde estas mulheres dificilmente encontrariam opção melhor, em um mercado legal, que suprisse suas necessidades e de sua família. 


\subsection{0 tráfico de drogas praticado pelas mulheres na Cidade de Santa Maria - RS}

Conforme os dados da Tabela 1, pode-se notar um crescimento considerável da população na Cidade de Santa Maria nos últimos 60 anos, visto que a população praticamente triplicou.

Tabela 1: População rural e urbana de Santa Maria

\begin{tabular}{c|c|c|c|c|c}
\hline Ano & Total & Urbana & $\%$ & Rural & $\%$ \\
\hline 1950 & 83.001 & 47.904 & 57 & 35.097 & 43 \\
1960 & 120.975 & 85.014 & 69 & 36.961 & 31 \\
1970 & 156.929 & 124.288 & 79 & 32.641 & 21 \\
1980 & 181.685 & 154.919 & 85 & 27.006 & 15 \\
1990 & 217.392 & 196.347 & 90 & 21.237 & 10 \\
2000 & 243.392 & 230.464 & 95 & 12.419 & 5 \\
2010 & 261.027 & 248.334 & 95 & 12.693 & 5 \\
\hline
\end{tabular}

Fonte: Bolfe (1997) / Censo IBGE (2010).

Para Melara (2012), esse aumento considerável da população nos últimos anos, se dá pela forte demanda de estudantes da Universidade Federal de Santa Maria por moradia na cidade e também pelo serviço da Base Área. Com o crescimento dos habitantes da cidade, a possibilidade de ocorrências de crimes e violência também se expandiu entre os moradores.

Segundo Melara (2012) em sua entrevista realizada em outubro de 2007 com o delegado da Delegacia de Furtos, Roubos, Entorpecentes e Capturas de Santa Maria - RS foi possivel compreender algumas informações acerca do funcionamento do tráfico e consumo de drogas na cidade. Segundo o autor, o delegado recomenda não confiar totalmente nos registros de ocorrências, pois o tráfico e o consumo de entorpecentes são crimes de muita mobilidade. Na entrevista ele também afirma que o fato de Santa Maria estar localizada no centro do Estado do Rio Grande do Sul faz da cidade uma rota para o tráfico e contribui para o aumento de crimes vinculados a esse tipo de crime.

Em entrevista com o delegado da Delegacia Regional de Santa Maria, realiza- 
da em 27 de junho de 2003 pelo jornal Diário de Santa Maria, o mesmo salienta que "o tráfico de drogas é o crime que mais coloca pessoas no Presídio Regional de Santa Maria, quem consome drogas acaba envolvido em furtos para conseguir dinheiro e manter o vício".

Melara (2012) conclui seu trabalho afirmando que, ainda que os bairros localizados no centro e região noroeste da cidade de Santa Maria mostrem números maiores em relação ao tráfico e consumo de drogas, estes crimes repartem-se por todo o município. Segundo ele, existe na cidade um grande potencial para a mobilidade da droga e este fato local inclui tanto traficantes como consumidores de qualquer classe social.

Pelos dados que seguem na Tabela 2, pode-se visualizar, de uma melhor forma, como os números dos registros de ocorrências acerca do crime de tráfico de drogas na cidade de Santa Maria - RS vem se comportando nos últimos onze anos, sem se especificar o sexo do praticante. É possivel verificar que a partir do ano de 2010 os números não mostram uma considerável queda para este tipo de crime na cidade e vem se mantendo altos em comparação com o período de 2006 a 2009, que tiveram os menores registros entre os anos de 2006 a 2016. O que se pode afirmar, com certeza, a partir do total de ocorrências registradas, é que o crime do tráfico de entorpecentes vem crescendo no período analisado, apresentando maiores picos em 2013 e 2014.

Tabela 2: Indicador Criminal de Tráfico de Drogas no Município de Santa Maria - RS (Número de ocorrências por ano)

\begin{tabular}{|c|c}
\hline Ano & Tráfico de Drogas \\
\hline 2006 & 59 \\
\hline 2007 & 87 \\
\hline 2008 & 74 \\
\hline 2009 & 80 \\
\hline 2010 & 125 \\
\hline 2011 & 202 \\
\hline 2012 & 163 \\
\hline 2013 & 245 \\
\hline 2014 & 243 \\
\hline 2015 & 201 \\
\hline 2016 & 202 \\
\hline
\end{tabular}

Fonte: SSP/RS (2006 a 2016). 


\section{Metodologia}

A unidade de estudo da pesquisa foi o Presídio Regional de Santa Maria, que se localiza no município de Santa Maria - RS, com o intuito de se analisar a luz da Teoria Econômica do Crime, os fatores determinantes de ingresso das mulheres no mercado do tráfico de drogas, com questões que respondessem como ocorre à entrada delas nesse crime. A partir da entrega de questionários para a coleta de dados, foi possivel obter respostas que atendessem aos objetivos específicos do trabalho e traçar um panorama acerca do grupo examinado. Os questionários foram elaborados com perguntas fechadas, obtendo várias alternativas de respostas com a intenção de auxiliar na obtenção das mesmas, e abertas, onde a interrogada podia escrever livremente sem ter que optar pelas opções propostas.

A população-alvo pesquisada foi de 13 mulheres presas e condenadas pelo crime de tráfico de drogas, de um total de 30 no momento da pesquisa, a se localizarem no Presidio Regional de Santa Maria - RS. Somente mulheres que foram julgadas e condenadas pelo crime de tráfico de drogas responderam ao questionário.

Os procedimentos necessários para a realização do questionário socioeconômico foi, em primeiro lugar, a conversação com o Presídio Regional de Santa Maria para verificar a possibilidade da realização do questionário nesse estabelecimento, em segundo lugar foi o envio da documentação necessária para o órgão responsável no Estado do Rio Grande do Sul, que seria a SUSEPE - RS, em terceiro lugar ocorreu à regulamentação desses documentos com as pesquisadoras para que o questionário pudesse ser feito. Após esses procedimentos, a SUSEPE - RS comunicou o Presídio Regional de Santa Maria da regulamentação dos documentos e da possibilidade da entrega do questionário socioeconômico na Penitenciária Regional de Santa Maria - RS. Após esses quatros passos, pôde-se dar início a pesquisa de campo, que levou por volta de duas semanas para ser concluída.

O questionário utilizado como base para a pesquisa foi uma adaptação do questionário utilizado por Shikida (2002) em seu trabalho na penitenciária de Piraquara no Paraná. Neste, em especial, buscou-se relacionar as variáveis apontadas por Shikida como sendo as responsáveis pelo interesse das pessoas em alocar seu tempo para cometer um ato ilícito. Desta forma, o questionário teve o intuito de destacar as características socioeconômicas das entrevistadas, como etnia, religião, estado civil, seu nível de escolaridade e de seus pais, sua ocupação profissional, além de questões que relacionassem como ocorreu sua decisão de cometer um crime.

Durante a aplicação dos questionários, no Presídio Regional de Santa Maria RS, a população total encarcerada era de 244 presos, entre homens e mulheres. Deste total, haviam 30 mulheres presas e condenadas pelo crime de Tráfico de Drogas em regime fechado. Aproximadamente $43 \%$ do total de mulheres presas 
pelo Tráfico de drogas no local concordaram em participar da pesquisa e responder os questionários (13 mulheres).

\section{Resultados}

Na primeira parte do questionário foram abordados preceitos gerais a respeito da realidade socioeconômicas das presas e seus familiares. A orientação sexual das entrevistadas foi de: $77 \%$ se consideravam heterossexuais, $15 \%$ de alguma outra orientação sexual que não estivesse especificada nas opções sugeridas, $8 \%$ não responderam e $0 \%$ se considerava homossexual, bissexual ou Transgênero. A etnia das entrevistadas (cor/raça) ficou dividida da seguinte forma: em maior número as entrevistadas se consideravam brancas representando $54 \%$ do total, $31 \%$ se consideravam pardas e $15 \%$ negras. As opções amarela, indígena e não sei/ não quero declarar tiveram $0 \%$ do total, conforme se verifica na Tabela 3 a seguir.

Tabela 3: Cor/raça

\begin{tabular}{l|l|l|l|l|l}
\hline 1.2 Cor/Raça & & & & & \\
\hline Branca & Preta & Parda & Amarela & Indigena & $\begin{array}{l}\text { Não sei/Não quero } \\
\text { declarar }\end{array}$ \\
\hline $54 \%$ & $15 \%$ & $31 \%$ & $0 \%$ & $0 \%$ & $0 \%$ \\
\hline
\end{tabular}

Fonte: Elaborado pelas autoras a partir dos resultados do questionário (2017).

De acordo com os valores apresentados, percebe-se que a variável etnia não refletiu as tendências descritas por muitos autores, de que a população afrodescendente constitui-se hoje como a maior população de condenados. Conforme destaca Santos Júnior e Oliveira $(2015$, p. 6) "fica evidente a possivel inserção do jovem negro no contexto da criminalidade, além da convivência num meio que a violência é predominante, é notório a inacessibilidade do mesmo a direitos e garantias fundamentais a qualquer cidadão". $O$ resultado obtido no presente questionário está de acordo com o Relatório Final da Comissão de Cidadania e Direitos Humanos Subcomissão da Situação Prisional do Estado do Rio Grande do Sul (2015, p.20) que ressalta que "apenas nos estados do sul do país, [...], a população prisional não é composta majoritariamente por pessoas negras". Essa questão pode ser explicada pelo fato de os estados do sul do Brasil terem maior concentração de pessoas brancas, comparado com o restante do país, conforme descreve a Sintese dos Indicadores Sociais de 2010 (IBGE).

No que diz respeito ao fator idade em que cometeu o crime, as respostas foram que 39\% das mulheres cometeram o crime de Tráfico de Drogas entre 21 e 
30 anos de idade, $31 \%$ entre 31 e 40 anos, seguidamente com 15\% entre 11 e 20 anos e também $15 \%$ sem resposta para esta pergunta. Tais percentuais podem ser visualizados no gráfico 2 abaixo.

Gráfico 2: Idade que tinha quando cometeu o crime

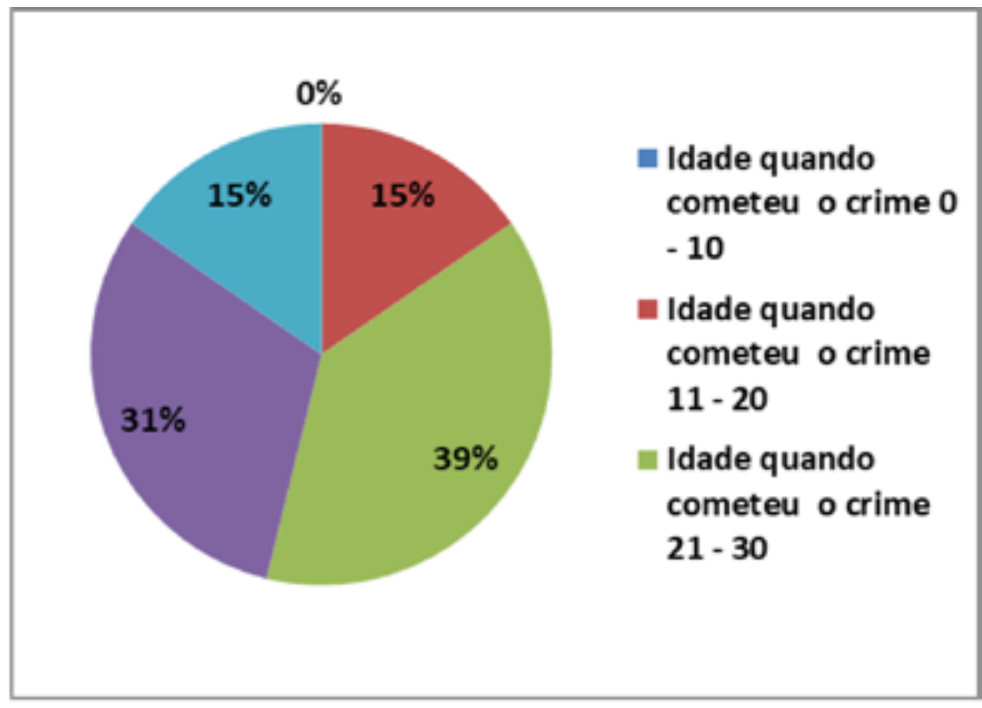

Fonte: Elaborado pelas autoras a partir dos resultados do questionário (2017).

Ainda que o percentual de mulheres que cometeram o crime entre 31 e 40 anos seja bastante expressivo, encontramos a maior tendência entre as idades de 21 e 30 anos, momento em que estas jovens estavam a entrar na vida adulta e provavelmente, em busca de seu primeiro emprego. Verifica-se tal fato na passagem destacada por Grogger (1995, apud SHIKIDA, 2009, p. 12) onde "a maior participação de jovens nas atividades criminais deve-se, sobretudo, aos menores indices salariais em que estão sujeitos, o que reduz o custo de oportunidade do individuo em migrar para o setor ilícito da economia".

Na pergunta "estado em que nasceu", não observou-segrande diversidade entre as entrevistadas e às opções que mais apresentaram expressividade foram: $85 \%$ pertenciam ao estado onde foram presas, ou seja, Rio Grande do Sul, $8 \%$ nasceram no estado vizinho de Santa Catarina e uma pessoa não respondeu.

A questão seguinte solicitava que as detentas identificassem a área de origem, rural ou urbano. Observou-se que $77 \%$ residiam na área urbana e $23 \%$ na área rural. Com isso, é notório que o êxodo rural não apresentou relação com a criminalidade, visto que o índice de mulheres com origem no meio urbano é três vezes maior que o número de mulheres de origem no meio rural; conforme se identifica no gráfico 3 a seguir. 


\section{Gráfico 3: Origem}

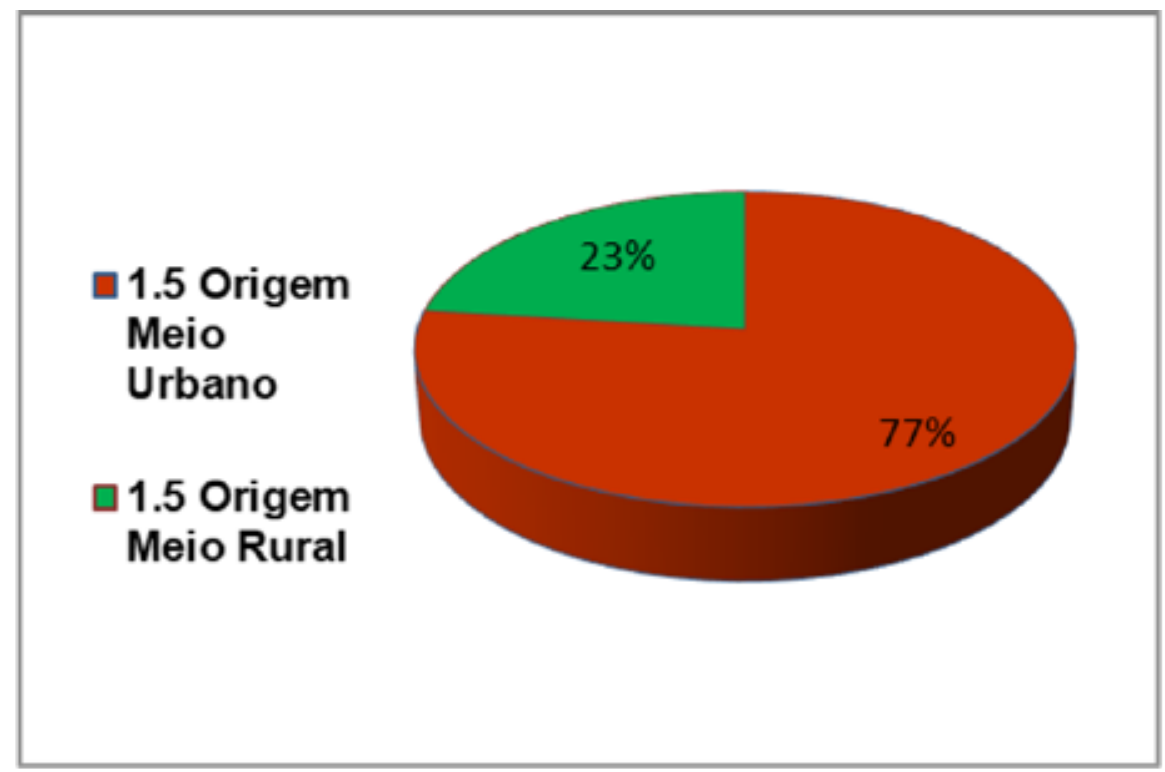

Fonte: Elaborado pelas autoras a partir dos resultados do questionário (2017).

Quanto ao questionamento sobre a crença ou não crença em Deus, segundo as mulheres questionadas $100 \%$ delas dizem acreditar em Deus, desse total $69 \%$ se dizem católicas, $15 \%$ espíritas, $8 \%$ evangélicas e uma pessoa não respondeu. Ainda no quesito religião, $62 \%$ das presas e condenadas por Tráfico de Drogas eram praticantes de sua religião, contra $38 \%$ não praticantes. $\bigcirc$ grande número de presas que até o momento do crime se consideravam praticantes de sua religião sugere que este ato não tem se mostrado importante a ponto de desistirem da prática criminosa. Sobre a mudança de religião após a reclusão, apenas 15\% das entrevistadas decidiu realizar tal mudança, contra $85 \%$ que optou por continuar na religião que já seguia até o momento da aprensão. Esses valores mostram que o fato das mulheres serem presas não as fez repensarem a respeito de sua religião.

No quesito nível de escolaridade, o que chama a atenção é o alto número de presas que tem somente ensino fundamental, com uma porcentagem que chega a $62 \%$, mais da metade das entrevistadas. Seguidamente, $23 \%$ das muIheres dizem ter ensino médio completo. Dentre as entrevistadas, uma delas diz "não ter instrução" e outra não respondeu esta questão. Conforme se vê no gráfico 4 a seguir. 
Gráfico 4: Nivel de escolaridade

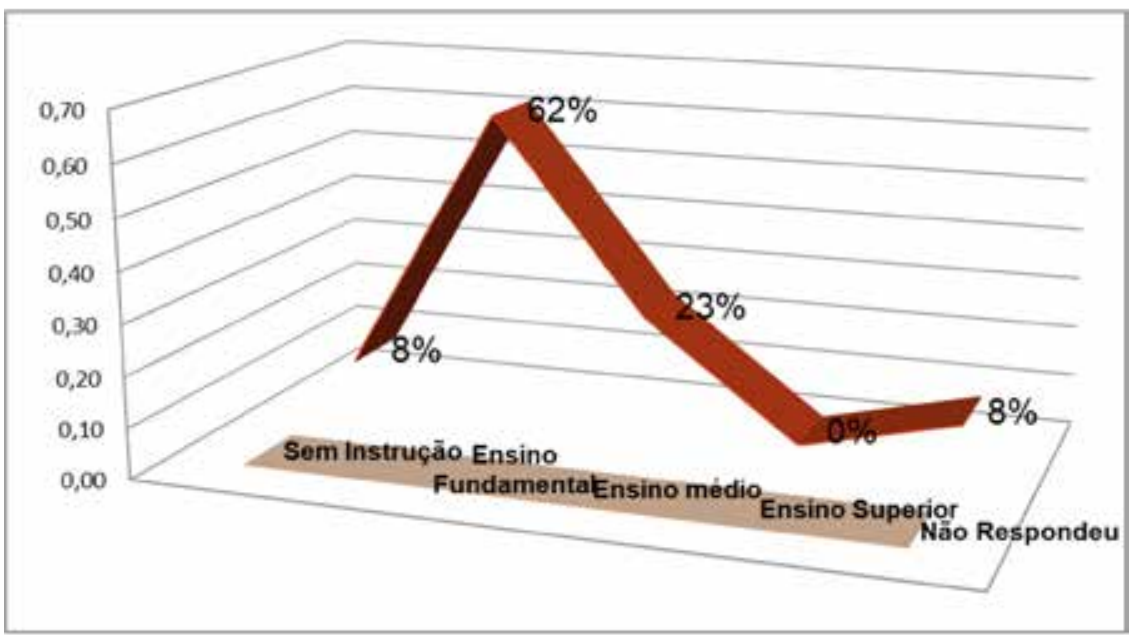

Fonte: Elaborado pelas autoras a partir dos resultados do questionário (2017).

A relação de crime e educação é um tema de grande polêmica na sociedade. Em forma de preconceito, atribui-se a indivíduos com menor nivel de educação maiores chances de se tornarem criminosos, em comparação com individuos com maiores níves de educação. Esta ideia é questionada a partir de vários estudos científicos, como o de Freeman (2003) que defende que a variável educação tem ligação com vários outros fatores, como a renda por exemplo. $O$ fator renda se relaciona com indivíduos que estudaram mais ou menos tempo, de modo em que, pessoas que estudaram mais, tem maior facilidade de conseguir uma boa remuneração salarial, em comparação com indivíduos que estudaram menos, por exemplo.

Nas questões que envolvem a variável educação é importante destacar ainda os motivos pelos quais as mulheres alegam terem largado os estudos. Como maior motivador tem-se fato delas começarem a contribuir com a renda de sua familia, representando $40 \%$ das entrevistadas, o segundo maior motivador seriam os problemas familiares com $20 \%$ do total, $13 \%$ o envolvimento com drogas, alcoolismo e crimes; $7 \%$ alegam não terem apoio ou descaso e $7 \%$ marcaram a opção casamento. Uma delas diz não ter largado os estudos, outra marcou a opção "outro" e uma das entrevistadas não respondeu a esta pergunta. Estes seriam os motivos elencados pelas mulheres do Presídio Regional de Santa Maria como razão para largarem os estudos, o que está relacionado ao alto indíce de mulheres neste local que tem apenas o ensino fundamental. Os fatores motivadores da paralisão dos estudos, conforme as opções do questionário, estão descritos no gráfico 5 a seguir. 
Gráfico 5: Motivo(s) pelo(s) quais interrompeu os estudos ${ }^{4}$

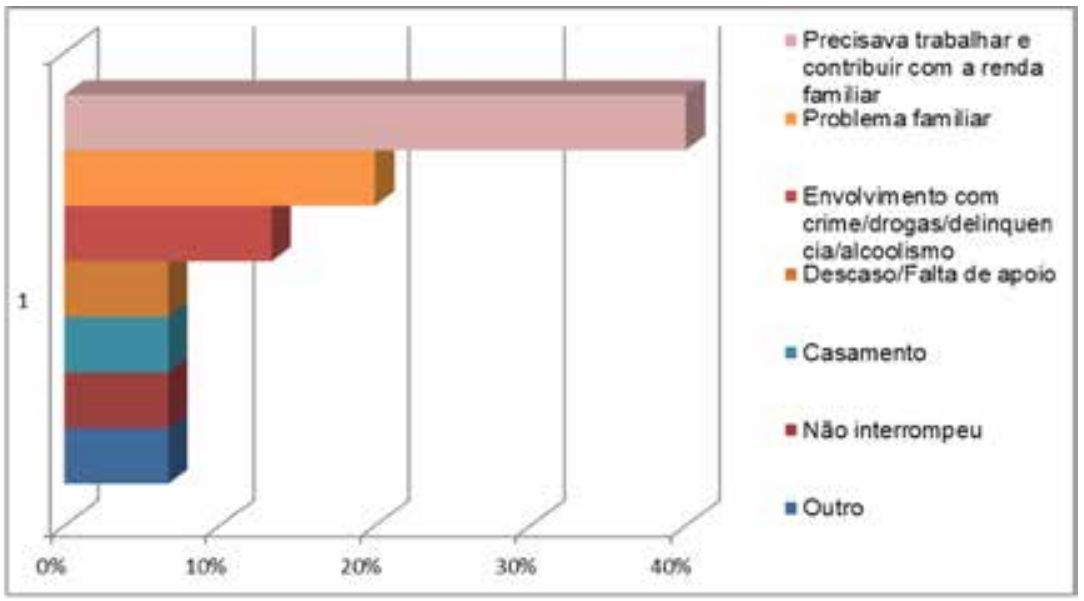

Fonte: Elaborado pelas autoras a partir dos resultados do questionário (2017).

Solicitou-se, em seguida, que as presas respondessem questões a respeito de sua família na época da prática do crime. Quanto ao seu estado civil na época, obteve-se as seguintes proporções: $69 \%$ das mulheres eram solteiras no momento em que foram presas e $31 \%$ eram casadas, as outras opções de estado civil não tiveram nenhuma marcação. Já na pergunta que as indigava sobre a existência de mais de uma relação estável, $85 \%$ delas confirmam que sim e 15\% que nunca tiveram mais de uma ou nenhuma.

Gráfico 6: Estado civil na época do crime

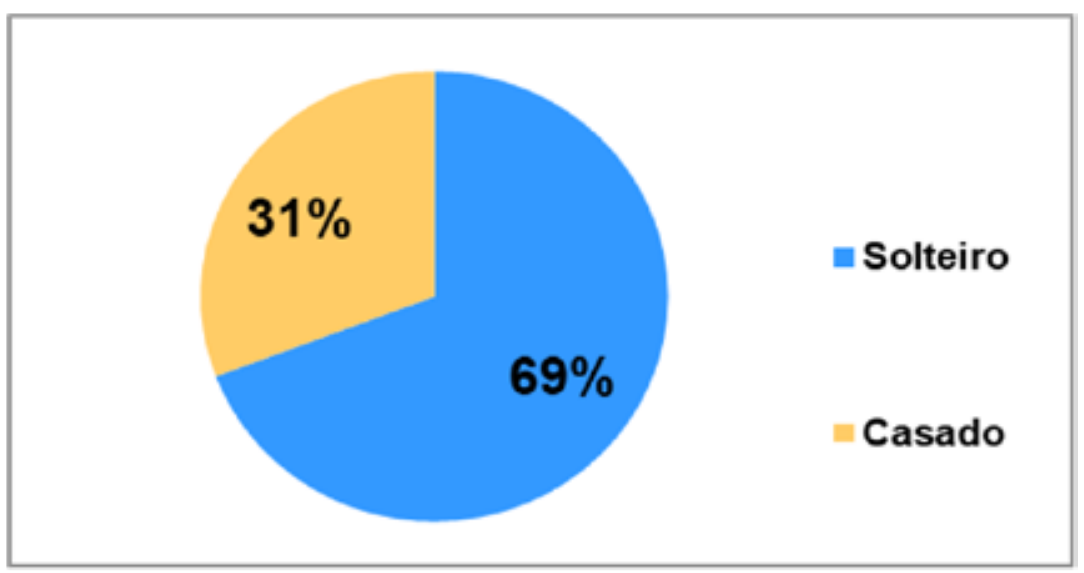

Fonte: Elaborado pelas autoras a partir dos resultados do questionário (2017). 
As questões que envolvem a estrutura familiar das mulheres presas e condenadas em regime fechado por tráfico de drogas são muito importantes para entender o histórico de suas ações e possiveis motivadores. Sabe-se que a presença da familia na definição do caráter de um indivíduo é fundamental, em especial, no que diz respeito ao ensinamento de bons valores e apoio para o bom convivio em sociedade. Assim, o bom convivio familiar pode ser um obstáculo para a atividade criminosa.

Gráfico 6: Estado civil na época do crime

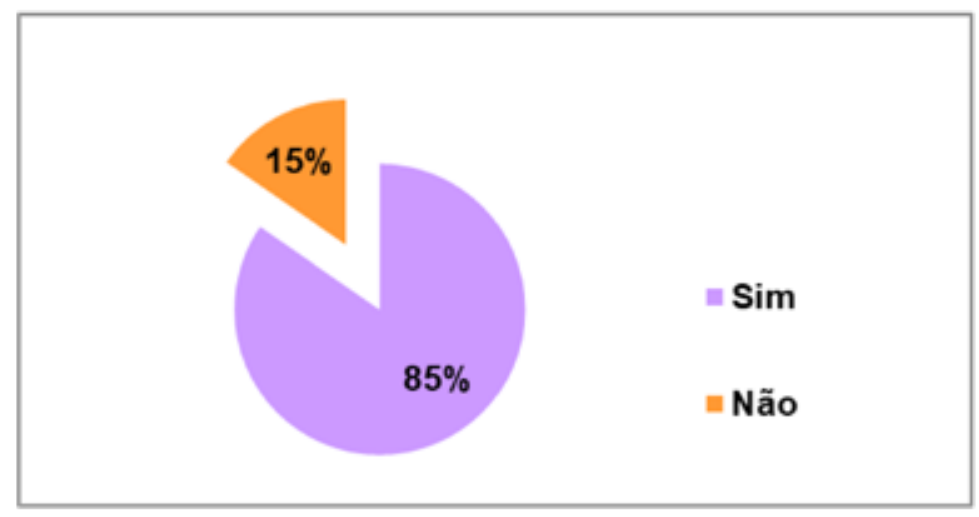

Fonte: Elaborado pelas autoras a partir dos resultados do questionário (2017).

Em relação a pergunta se seus pais (um ou os dois) estavam trabalhando na época da prática do crime, $69 \%$ responderam que sim e $23 \%$ que não, uma pessoa não respondeu a esta questão. Esta opção pode estar interligada com a pergunta feita anteriormente sobre os motivadores da paralização dos estudos, onde o maior influenciador foi a necessidade de contribuir com a renda familiar. Considerando que mais da metade dos pais trabalhavam na época e que, mesmo assim, a maioria das mulheres teve que largar seus estudos para ajudar financeiramente a familia, se observa o fator econômico renda como forte "motivador" para o caminho do crime no caso dessas mulheres. Abaixo é possivel visualizar quais profissões as mulheres atribuíram aos seus pais e mães.

Tabela 4: Ocupação dos pais das entrevistadas

\begin{tabular}{c|c|c|c|c|c}
\hline Agricultor & Falecido & Aposentado & $\begin{array}{c}\text { Funcionário } \\
\text { Público }\end{array}$ & Pedreiro & Caminhoneiro \\
\hline 2 & 2 & 2 & 2 & 4 & 1 \\
\hline $15 \%$ & $15 \%$ & $15 \%$ & $15 \%$ & $31 \%$ & $8 \%$ \\
\hline
\end{tabular}

Fonte: Elaborado pelas autoras a partir dos resultados do questionário (2017). 
Tabela 5: Ocupação das mães das entrevistadas

\begin{tabular}{l|l|l|l|l}
\hline Do lar & Agricultora & Não respondeu & Funcionária Pública & Doméstica \\
\hline 6 & 1 & 1 & 1 & 4 \\
\hline $46 \%$ & $8 \%$ & $8 \%$ & $8 \%$ & $31 \%$ \\
\hline
\end{tabular}

Fonte: Elaborado pelas autoras a partir dos resultados do questionário (2017).

Observando as tabelas das ocupações profissionais dos pais das mulheres presas, nota-se que estas mostram uma realidade de renda moderada, fator que pode ser explicado pelo baixo nível de escolaridade que seus pais apresentam. Os mais baixos indicadores de escolaridade tem as mais altas porcentagens: $46 \%$ apresenta nivel fundamental incompleto, $38 \%$ marcou a opção "sem instrução", $15 \%$ ensino fundamental incompleto e $8 \%$ ensino superior incompleto.

Gráfico 8: Nivel de escolaridade dos pais

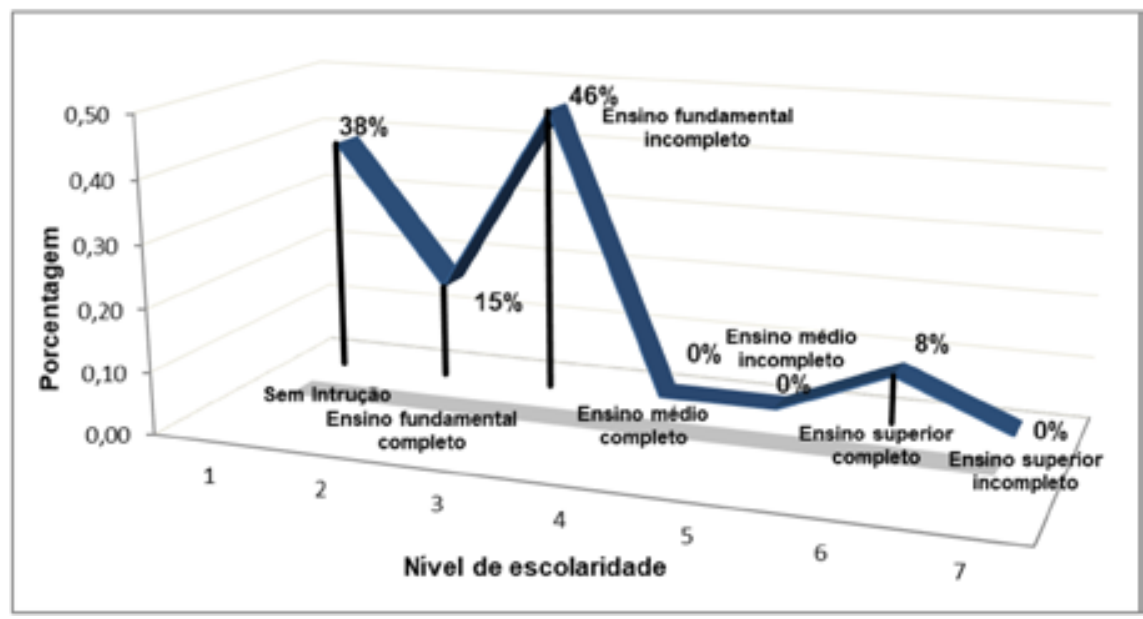

Fonte: Elaborado pelas autoras a partir dos resultados do questionário (2017).

No que se refere as suas famílias, ainda foi solicitado que elas respondessem se seus pais estavam casados até o ocorrência do crime, $69 \%$ delas respondeu que não e $23 \%$ que sim, uma delas não respondeu a esta questão. Também foi questionado se existia em sua familia algum antecedente criminal, $54 \%$ responderam que sim e $46 \%$ que não haviam antecedentes na família.

Durante sua infância, $54 \%$ das detentas afirmarm que seus pais estavam presentes, contra $46 \%$ afirmando que não, percentuais com pouca discrepância, mostrando realidades distintas entre as mulheres que participaram da pesquisa. No que se refere a família, ainda se questionou se pai, mãe ou ambos faziam uso 
de álcool, cigarro, ou alguma outra droga; $62 \%$ delas afirmaram que não e $38 \%$ que sim. Sobre aspectos socieconômicos ainda foi solicitado que elas respondessem se faziam uso de bebida alcóolica, drogas ou cigarros. $69 \%$ das mulheres afirmaram fazer uso de bebida alcólica, contra $31 \%$ que não fazia uso. $54 \%$ delas disse que fumava ou ainda fuma cigarros, contra $46 \%$ que respondeu não a esta pergunta. Quanto ao uso de drogas, $54 \%$ disse que não utilizava e $46 \%$ afirmaram que sim.

Gráfico 9: Possui antecedente criminal na família

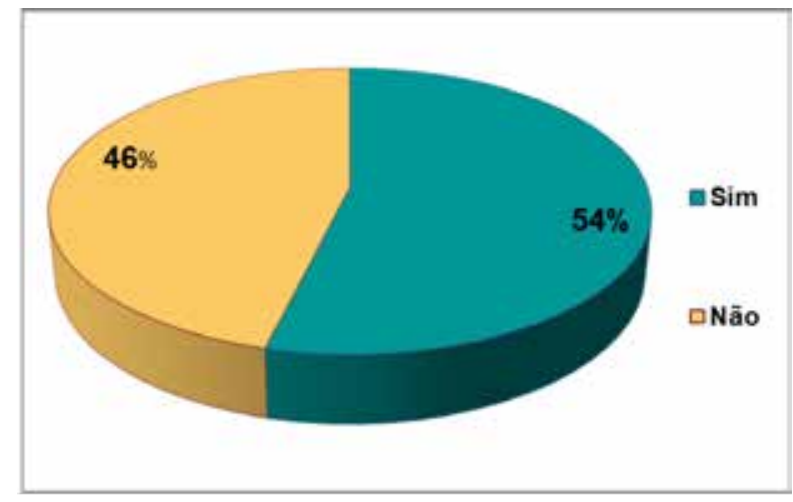

Fonte: Elaborado pelas autoras a partir dos resultados do questionário (2017).

Gráfico 10: Você fazia uso de bebida alcóolica, fazia/faz uso de cigarros e fazia uso de drogas

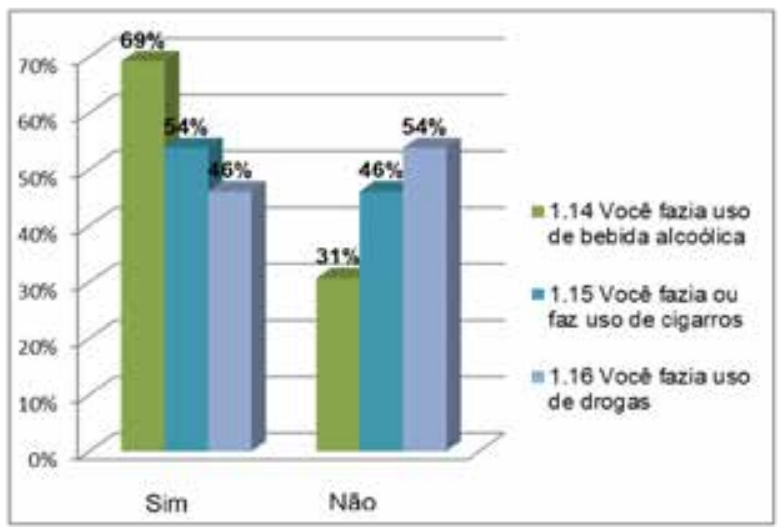

Fonte: Elaborado pelas autoras a partir dos resultados do questionário (2017).

As informações sobre o uso de drogas, alcóol e cigarro, vícios esses que geram uma forte dependência de seus usuários, juntamente com aspectos familiares, revelam fatores que, possivelmente, podem ser associados a criminalidade. Sabe-se que uma boa base familiar, que repassa bons costumes, ensinamentos e 
dá apoio, forma indivíduos mais preparados para os problemas do dia a dia, além de seus membros terem menores chances de se envolver com a criminalidade se comparados com individuos sem uma forte estrutura familiar.

As próximas questões do questionário socioeconômico tratam apenas de aspectos relacionados ao crime. A primeira pergunta da segunda parte, questionou as mulheres sobre qual era o crime por elas cometido no momento do flagrante. $92 \%$ das entrevistadas alegou estar cometendo o crime de tráfico de drogas e $8 \%$ disse estar cometendo latrocínio. Conforme descreve Picon (2015) " o latrocínio ocorrerá, portanto, quando o agente se utilizar de violência (apenas) para subtração da coisa alheia e o agredido vier a óbito ". Como todas as entrevistadas estavam condenadas em regime de clausúra por tráfico de drogas, o valor de $8 \%$ refere-se somente ao flagrante, assim como $\circ 92 \%$ não descarta o cometimento de outros crimes.

Em seguida foi solicitado que elas respondessem se o crime foi cometido com ou sem parceiro, $77 \%$ afirmaram que sim, houve a participação de parceiro no crime, contra $23 \%$ que afirmaram não existir parceiro no ato criminoso. Shikida e Borilli (2007, p.18) obtiveram números parecidos "em relação a isto - a ação dos criminosos no tocante à formação de grupos -, dados da pesquisa demonstram que $72,52 \%$ agiam em grupo e $27,48 \%$ agiam isoladamente, ou seja, não possuíam parceiros para a prática criminosa". Segundo os pesquisadores Fernandes e Chofard (1995, apud Shikida e Borilli, 2007, p.18) "[...] é preciso considerar que o crime organizado possui certa estrutura empresarial para a realização de atividades ilícitas, articulando fatores de produção (capital, pessoal e especialização tecnológica) [...]".

A próxima questão indagou se houve reincidência que, para Jesus (2013, p.611) "reincidência deriva de recidere, que significa recair, repetir o ato. Reincidência é, em termos comuns, repetir a prática do crime". Os resultados indicam que $46 \%$ das mulheres são reincidentes e $46 \%$ não. A pesquisa de Shikida e Borilli (2007), não fez distinção de sexo entre os entrevistados e se aplicou a qualquer crime econômico. Nela os autores observaram um percentual maior de reincidentes, chegando a um valor de $65,27 \%$ entre os entrevistados.

Sobre conhecer a vítima, $46 \%$ das entrevistadas não responderam a esta questão, seguido de $31 \%$ que dizem não conhecer a vítima e $23 \%$ que conhecem a vítima. Shikida e Borilli (2007) também tiveram, na aplicação do questionário, um número maior de entrevistados que diziam não conhecer a vítima, na pesquisa deles $75,57 \%$ dos indivíduos que cometeram crime não conheciam a vítima e $24,43 \%$ disseram conhecer. Quanto a esta questão, os autores ainda destacaram que "segundo as respostas dos entrevistados, os ambientes, os hábitos e as evidências externas de riqueza das vítimas eram consideradas como "iscas" para a atuação dos mesmos". (SHIKIDA e BORILLI, 2007, p.19).

Solicitou-se, em seguida que as entrevistadas especificassem os motivos que as levaram a praticar o crime, nesta pergunta elas poderiam listar mais de um mo- 
tivo. Os números obtidos foram: $22 \%$ alegaram falta de oportunidade, $13 \%$ por estarem desempregadas e também $13 \%$ das entrevistadas precisavam ajudar no orçamento familiar, porque estavam desempregadas. $9 \%$ alegou cometer - crime por indução de amigos, 9\% para manter algum vício como drogas e álcool e também $9 \%$ alegou que o motivo foi status/cobiça/ganância/ganho fácil. As menores opções marcadas foram baixo nivel de escolaridade e dificuldade financeira, ambas com 4\%. Os motivos elencados pelas presas podem ser visualizados no gráfico 11.

Gráfico 11: Qual (is) o(s) motivo(s) que te levou a praticar a(s) atividade(s) criminosa(s)

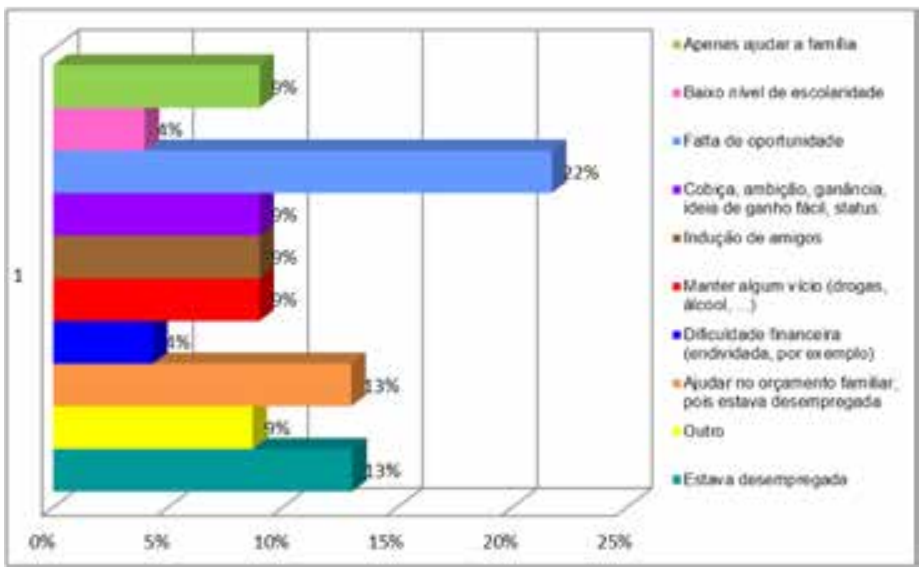

Fonte: Elaborado pelas autoras a partir dos resultados do questionário (2017).

O fato de estarem desempregas e precisarem contribuir com a renda familiar, sugere que melhores empregos, com maiores salários, pode contribuir para prevenir a entrada das pessoas ao mundo do crime. No estudo de Shikida e Borilli (2007), as respostas do questionário sugerem conclusões semelhantes "vale frisar que dados da pesquisa indicaram que a dificuldade financeira, o desemprego e a necessidade de ajudar no orçamento familiar contribuíram para que $29,38 \%$ dos entrevistados praticassem crimes" (SHIKIDA e BORILLI, 2007, p. 20).

Sobre os motivos que as levaram a prática criminosa, ainda é importante destacar as possiveis influências, seja de amigos, parentes ou parceiros/cônjuges. Quando perguntado se houve algum antecedente criminal na familia, 54\% afirmaram que sim e $9 \%$ marcou a indução de amigos. Dessa forma, a "influência de terceiros" foi determinante para as escolhas. Nesta questão, ainda cabe relacionar o fato de $77 \%$ das mulheres afirmarem cometer o crime com parceiro. Este resultado demonstra o quanto a vida em sociedade transforma as pessoas, 
tanto para o bem quanto para o mal, em questões de escolhas e atitudes, além de evidenciar o papel primordial que a familia estabelece no caráter dos indivíduos.

As seguintes perguntas trataram da vida profissional da presa, questões também muito importantes para a análise. $54 \%$ das mulheres que responderam o questionário, disseram não estar trabalhando na época da prática do crime, contra $46 \%$ que afirmaram estar em algum tipo de emprego. Nessa divisão, somente $23 \%$ das mulheres tinham carteira assinada e $85 \%$ delas afirmou que sua renda não cobria as despesas básicas. A respeito da ocupação profissional na época do crime, $29 \%$ estavam desempregadas, $21 \%$ eram diaristas e $14 \%$ garotas de programa. Estes valores mostram o quanto é relevante a relação crime e desemprego, visto que a maioria das mulheres presas e condenadas em regime fechado por tráfico de drogas na cidade de Santa Maria - RS estavam desempregadas. $O$ ato de cometer um crime para estas mulheres não apresentava grande risco, visto que, estas já se encontravam desempregadas. O risco era, em grande probabilidade, não fazer nada para melhorar sua situação e de sua família. $O$ fator desemprego confirma a teoria de que menores oportunidades no mercado de trabalho influenciam o crime, assim como, a inexistência de renda diminui o custo de oportunidade de estar presa. As profissões por elas elencadas podem ser meIhores visualizadas na tabela 6 a seguir.

Tabela 6 : Qual a sua ocupação profissional na época da prática do crime

\begin{tabular}{l|l}
\hline Desempregada & $29 \%$ \\
\hline Garota de programa & $14 \%$ \\
\hline Vendedora & $7 \%$ \\
\hline Diarista & $21 \%$ \\
\hline Garçom & $7 \%$ \\
\hline Recicladora & $7 \%$ \\
\hline Dona de casa & $7 \%$ \\
\hline Não respondeu & $7 \%$ \\
\hline
\end{tabular}

Fonte: Elaborado pelas autoras a partir dos resultados do questionário (2017).

A próxima questão indagou as presas sobre os fatores que levaram ao insucesso de sua atividade criminosa. O principal fator apontado foi a denúncia com $39 \%$, seguido de investigação com $17 \%$, ação da polícia com $11 \%$ e um grande número de presas não respondeu (11\%), dados esses, conforme o gráfico 12 . 
Gráfico 12 : Quais os fatores que levaram ao insucesso de sua atividade criminosa.

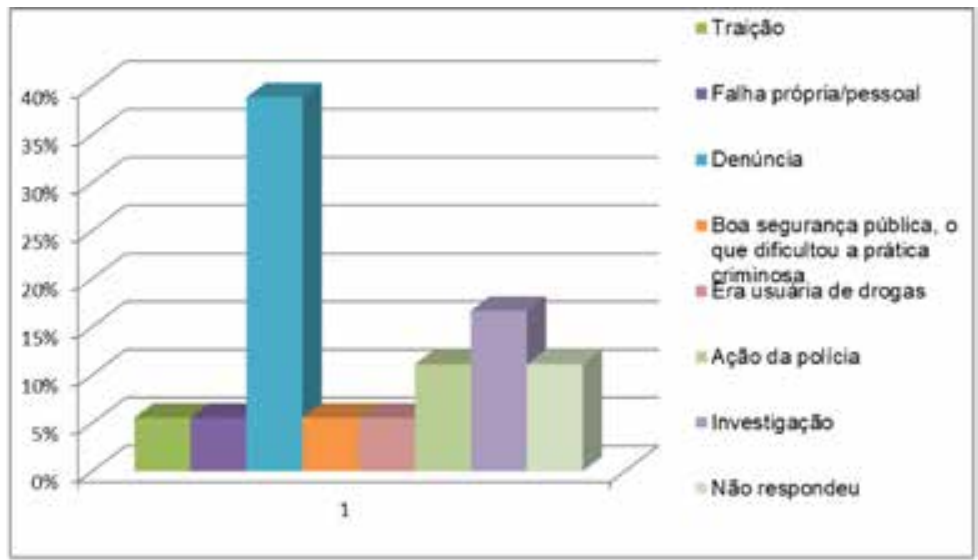

Fonte: Elaborado pelas autoras a partir dos resultados do questionário (2017).

A pesquisa feita por Shikida e Borilli (2007) chegou a números semelhantes e apontou como principal fator para o insucesso a denúncia, para 43,9\% das entrevistadas, seguido da ação da polícia, com $37,4 \%$, e da falha própria com $19,85 \%$.

Em seguida foi questionado se já houve alguma tentativa de fuga, $92 \%$ afirmou que não, contra $8 \%$ que disse já ter tentado fuga. Sobre a existência de acesso a algum tipo de arma, $62 \%$ confirma já ter tido acesso. Esta aproximação com a arma de fogo, em especial, na prática de crimes econômicos, dá aos criminosos a ideia de ganho fácil, liberdade de escolhas e coragem para um possivel enfrentamento com a vítima, conforme descreve Zaluar (2004). Quanto à pergunta se já foi vítima de algum tipo de crime, somente $29 \%$ declarou não ter sido vítima de nenhum crime e $7 \%$ não respondeu a esta questão. $64 \%$ das mulheres afirmaram já ter sido vítimas de algum crime, sendo estes os mais variados, conforme a tabela 7 .

Tabela 7 : Já foi vítima de algum tipo de crime

\begin{tabular}{l|l|l|l|l|l|l|l}
\hline Assalto & Não & $\begin{array}{l}\text { Violência } \\
\text { Doméstica }\end{array}$ & $\begin{array}{l}\text { Abuso de } \\
\text { autoridade }\end{array}$ & $\begin{array}{l}\text { Sim, não quis } \\
\text { declarar }\end{array}$ & Agressão & Estupro & $\begin{array}{l}\text { Não } \\
\text { respondeu }\end{array}$ \\
\hline $7 \%$ & $29 \%$ & $21 \%$ & $14 \%$ & $7 \%$ & $7 \%$ & $7 \%$ & $7 \%$ \\
\hline
\end{tabular}

Fonte: Elaborado pelas autoras a partir dos resultados do questionário (2017).

Entre os questionários respondidos, $62 \%$ das mulheres disseram não ter outros antecedentes criminais antes de serem presas. Das mulheres que já possuíam antecedentes criminais no momento da apreensão, $23 \%$ acreditam que a prática de outros crimes não é influenciada pelo tráfico de drogas. 


\section{Considerações Finais}

Este estudo buscou descrever quais os fatores que influenciam o ingresso das mulheres no mercado do tráfico de drogas do município de Santa Maria - RS. Para isso, realizou-se um estudo de caso no Presídio Regional de Santa Maria, único local da cidade e da região central que recebe mulheres presas. Segundo o departamento técnico do presídio, no momento da aplicação do questionário, haviam por volta de 30 mulheres presas e condenadas em regime fechado por tráfico de drogas. Desse total, foram analisadas as respostas dadas no questionário de 13 mulheres que cumpriam pena naquele momento e concordaram em participar da pequisa.

Observou-se que a maioria das mulheres que responderam ao questionário eram jovens, brancas, solteiras e do meio urbano (cidade). A maioria delas também faz/fazia uso de álcool e cigarros. Quanto a fé/religião, todas afirmaram acreditar em Deus e, em geral, eram católicas, praticantes e não mudaram de religião após a reclusão. A escolaridade das mulheres presas se concentrou no ensino fundamental e a maioria desistiu dos estudos por precisar trabalhar e, assim, contribuir com a renda da família, porém seus salários não eram suficientes para cobrir as despesas básicas.

Em maior parte, as mulheres estavam solteiras quando cometeram o crime, mas o realizaram com parceiro e já tiveram mais de um relacionamento estável. Sobre suas famílias, a maioria delas aparenta ser desestruturada, visto que mais da metade das mulheres não tinha algum de seus pais presentes na infância e possuíam antecedentes criminais na família, como pai, mãe elou irmãos. Predominaram os pais que trabalhavam, não eram casados no momento do crime e tinham apenas ensino fundamental incompleto. No momento do flagrante do crime, a maioria absoluta das mulheres cometia o tráfico de drogas, metade eram reincidentes e o motivo que mais levou a prática criminosa foi a falta de oportunidade. Essas mulheres não trabalhavam e por isso não tinham carteira assinada. Não possuíam antecedentes criminais e o principal fator para o insucesso de sua atividade criminosa foi a denúncia. Nunca tentaram fuga, já tiveram acesso a algum tipo de arma e já foram vítimas de algum tipo de crime.

Assim, conclui-se que o fator renda é o principal motivador para a entrada dessas mulheres no mundo do crime e do tráfico de drogas, dado que a maioria das mulheres encontrava-se desempregada e, por conta disso, sua renda não cobria as despesas básicas. $O$ baixo nivel de escolaridade de seus pais foi repassado para elas, o que, consequentemente influenciou em sua renda. A falta de oportunidade, também se liga ao fato de terem um baixo nivel de escolaridade, mas pode igualmente estar relacionado a simples razão delas serem mulheres. Conforme já verificado em outros estudos científicos, muitas vezes, as mulheres acabam praticando atividades subalternas no tráfico de drogas e se tornam o elo mais vulnerável. A influência da família e de algum parceiro na prática do crime, 
já descrita por alguns autores, é confirmada na pesquisa, visto que a maioria delas confirmou a participação de um parceiro e de antecedentes criminais na família.

\section{Referências}

BARCINSKI, M. Centralidade de gênero no processo de construção da identidade de mulheres envolvidas na rede do tráfico de drogas. Ciência \& Saúde Coletiva, 14(5):1843-1853, 2009.

BARROS, A. M.; MACIEL, A. M. S. B.; FREIRE, I. R.; JORDÃO, M. P. D. Criminalidade e análise de gênero: a mulher e o crime. Um Estudo na penitenciária de Garanhuns -PE. 2007

CERVO, A. L.; BERVIAN, P. A. Metodologia científica. São Paulo: Prentice Hall, 2002.

COMISSÃO DE CIDADANIA E DIREITOS HUMANOS. Relatório da subcomissão com diagnóstico do sistema prisional do estado do Rio Grande do Sul, análise crítica e proposições. Porto Alegre, agosto 2015.

DEPEN. Levantamento Nacional de Informações Penitenciárias. IN FOPEN, 2005. Acessado a última vez em: nov./2016

DEPEN. Levantamento Nacional de Informações Penitenciárias INFOPEN, 2014. Ministério da Justiça. Disponível em: https://www.justica.gov.br/noticias/ mj-divulgara-novo-relatorio-do-infopen-nesta-terca-feira/relatorio-depen-versao-web.pdf. Acessado: nov./2016.

DUTRA, T. C. A criminalidade feminina com relação ao tráfico de drogas, frente à lei 11.343/06. 2012. Disponivel em:

http://www3.pucrs.br/pucrs/files/uni/poa/direito/graduacao/tcc/tcc2/trabaIhos2012_2/thaise_dutra.pdf Acessado nov./2016.

IBGE. Sintese dos Indicadores Sociais, 2010 -População total e respectiva distribuição percentual, por cor ou raça, segundo as Grandes Regiões, Unidades da Federação e Regiões Metropolitanas -2009.

JACINTO, D. Mulheres presas por tráfico de drogas e a ética do cuidado. Sociais E Humanas, Santa Maria, v. 24, n. 02, jul/dez, p. 36-51, 2011.

JESUS, D. Direito Penal Vol. 1 - Parte Geral. São Paulo: Saraiva, 36ª Ed. 2015.

MELARA, E., A espacialização da violência criminal na cidade de Santa Maria, RS. Confins [Online], 14, 2012. Disponível em: http://confins.revues.org/7477; DOI: 10.4000/confins.7477 Acessado: out./2017. 
MINISTÉRIO DA SAÚDE - Sistema de Informações sobre Mortalidade (SIM). 2014. Disponivel em: http://portalsaude.saude.gov.br/index.php/o-ministerio/ principal/secretarias/svs/mortalidade. Acessado pela última vez: out./2016.

MINZON, C. V.; DANNER, G. K.; BARRETO, D. J. Sistema prisional: conhecendo as vivências da mulher inserida neste contexto. Akrópolis Umuarama, v. 18, n. 1. 2010. Disponivel em: http://revistas.unipar.br/akropolis/article/viewFile/3118/2212. Último acesso em: out./2016.

MOURA, M. J. Porta Fechada, Vida Dilacerada: [AB1] Mulher, Tráfico de Drogas e Prisão: Estudo Realizado no Presídio Feminino do Ceará. Dissertação de mestrado apresentada no Mestrado em Políticas Públicas e Sociedade da Universidade Estadual do Ceará, 2005.

MUSUMECI, B. Mulher e violência no sistema de justiça criminal. Trabalho e Sociedade - Ano $1-N^{\circ} 2,2001$.

RODRIGUES, V. I.; HECHLER, A. D.; HENRICH, G.; KRAEMER, L. Gênero e privação de liberdade: as condições de vida das mulheres na prisão. Revista de Iniciação Científica da ULBRA - Nº10, 2012.

PICON, R. Do evento morte ocorrido no contexto do crime de roubo e a aplicação das penas do latrocínio. Revista Jus Navigandi, ano 20, n. 4383, 2 jul. 2015.

SHIKIDA, P. F. A. Economia do crime: teoria e evidências empíricas a partir de um estudo de caso na Penitenciária Estadual de Piraquara (PR). Revista AMDE, v.1, 2009.

SHIKIDA, P.F.; BORILLI, S.P. Economia do crime: estudo de casos nas penitenciárias paranaenses, 2007. Disponivel em: https://www.ufrgs.br/ppge/wp-content/themes/PPGE/page/textos-para-discussao/pcientifica/2007_06.pdf

SIMON, D. C.; SHIKIDA, P. F.; BORILLI, S. P. Economia do Crime: Uma Análise de Gênero a Partir de um Estudo de Caso na Penitenciária Feminina de Piraquara (PR). Revista De Estudos Sociais, Ano 7v. 12 n. 1e 22005.

STEFFENSMEIER, D. J.; COBB, M. J. Sex Differences in UrbanArrestsPaterns, 1934-1979. Social Problems, v.29 Issue:1, 1981.

UNODC. Relatório Mundial sobre Drogas. Escritório sobre Drogas e Crime das Nações Unidas, 2004. Disponivel em: http://www.unodc.org/pdf/WDR_2004/ volume_1.pdf. Acessado pela última vez: out./2016.

UNODC. Relatório Mundial sobre Drogas. Escritório sobre Drogas e Crime das Nações Unidas, United Nations Office onDrugsand Crime/Brazil. 2012. Disponivel em http://www.unodc.org/gsh/ Acessado pela última vez: nov./2016. 
UNODC. Relatório Mundial sobre Drogas. Escritório sobre Drogas e Crime das Nações Unidas, 2013. Disponivel em: https://www.unodc.org/lpo-brazil/pt/ frontpage/2013/06/26-world-drug-report-notes-stability-in-use-of-traditional-drugs-and-points-to-alarming-rise-in-new-psychoactive-substances.html. Acessado pela última vez: nov./2016.

ZALUAR, A. Integração perversa: pobreza e tráfico de drogas. Rio de Janeiro: FGV, 2004.

Recebido em março de 2018.

Aprovado em dezembro de 2018. 